This item was submitted to Loughborough's Research Repository by the author.

Items in Figshare are protected by copyright, with all rights reserved, unless otherwise indicated.

\title{
Exploitative learning and entrepreneurial orientation alignment in emerging young firms: implications for market and response performance
}

\section{PLEASE CITE THE PUBLISHED VERSION}

https://doi.org/10.1111/j.1467-8551.2007.00519.x

\section{PUBLISHER}

John Wiley \& Sons (@ British Academy of Management)

VERSION

AM (Accepted Manuscript)

\section{PUBLISHER STATEMENT}

This work is made available according to the conditions of the Creative Commons Attribution-NonCommercialNoDerivatives 4.0 International (CC BY-NC-ND 4.0) licence. Full details of this licence are available at: https://creativecommons.org/licenses/by-nc-nd/4.0/

\section{LICENCE}

CC BY-NC-ND 4.0

\section{REPOSITORY RECORD}

Hughes, Mathew, Paul Hughes, and Robert E. Morgan. 2019. "Exploitative Learning and Entrepreneurial Orientation Alignment in Emerging Young Firms: Implications for Market and Response Performance". figshare. https://hdl.handle.net/2134/26363. 


\title{
EXPLOITATIVE LEARNING AND ENTREPRENEURIAL ORIENTATION ALIGNMENT IN EMERGING YOUNG FIRMS: IMPLICATIONS FOR MARKET AND RESPONSE PERFORMANCE
}

\author{
Submitted to: British Journal of Management \\ BJM MS 05-139 \\ First submitted: November 2005 \\ First resubmission: May 2006 \\ Conditional acceptance: July 2006 \\ Mathew Hughes ${ }^{1}$ \\ University of Nottingham \\ Nottingham University Business School \\ Jubilee Campus, Wollaton Road \\ Nottingham NG8 1BB \\ United Kingdom \\ Tel: 01158467747 \\ Fax: 01158466650 \\ E-mail: mat.hughes@nottingham.ac.uk
}

\author{
Paul Hughes \\ Loughborough University \\ The Business School \\ Loughborough \\ Leicestershire LE11 3TU \\ United Kingdom \\ Tel: 01509228274 \\ Fax: 01509223962 \\ E-mail: p.hughes@lboro.ac.uk
}

\section{Robert E. Morgan}

Cardiff University

Cardiff Business School

Colum Drive

Cardiff CF10 3EU

United Kingdom

Tel: 02920870001

Fax: 02920874419

E-mail: morganre@cardiff.ac.uk

Acknowledgements: We are grateful to Duane Ireland for his advice and guidance on the theoretical aspects of this research project. We also acknowledge United Kingdom Business Incubation, in particular its Deputy Chief Executive, Peter Harman, for supporting the fieldwork. We also thank the three anonymous $B J M$ reviewers for their constructive comments.

\footnotetext{
${ }^{1}$ Corresponding author.
} 


\title{
EXPLOITATIVE LEARNING AND ENTREPRENEURIAL ORIENTATION ALIGNMENT IN EMERGING YOUNG FIRMS: IMPLICATIONS FOR MARKET AND RESPONSE PERFORMANCE
}

\begin{abstract}
We examine exploitative learning and entrepreneurial orientation in emerging young hightechnology firms located within business incubators. In the last five years, the U.K. government has invested approximately $£ 125 \mathrm{~m}$ in incubation activities. The rationale for supporting business incubation is to maximise knowledge sharing across firms with an expectation that it will leverage performance. This represents exploitative learning - the acquisition of established knowledge that carries clear known value and outcomes. Paradoxically, research into entrepreneurial orientation (EO) has repeatedly emphasised the value of knowledge created through exploratory learning mechanisms ("play, discovery and experimentation") in securing advantage. Theoretical and empirical questions are raised herein with regard to the value of exploitative learning within a network context which might negatively influence the impact of EO on the firm. Using configuration theory, we demonstrate that firms cannot sustain dual-dominant orientations of exploitative learning and EO. A strongly-configured EO generates high performance returns. However, multi-group analysis reveals that these effects are particularly strong for those firms whose exploitative learning is weak. Implications and directions for future research are discussed.
\end{abstract}




\section{INTRODUCTION \& BACKGROUND}

Emerging young firms, handicapped by liabilities of newness, face two important strategic challenges: (i) how to expand effectively the firm's knowledge base to compete intelligently (Yli-Renko, Autio and Sapienza, 2001); and, (ii) how to maximise gains from an entrepreneurial orientation (EO) (Wiklund and Shepherd, 2003). A strategic response to the first challenge is network learning. A growing stream of research advocates the use of network relations (Hite and Hesterly, 2001) and networked incubators (Hansen, Chesbrough, Nohria and Sull, 2000) as means for young firms to learn, acquire and share knowledge quickly. A networked incubator is not just a housing facility for emerging young firms but serves as a hub for such firms to quickly and repeatedly network with other similar firms, onsite business assistance organisations and any other outside firm brought into the strategic network by the incubator’s management team (Bøllingtoft and Ulhøi, 2005). Networked incubators allow emerging young firms to access a wealth of potential partners which can be repeatedly tapped to acquire knowledge (Hansen et al., 2000). Such continuous exposure to learning opportunities can improve the capacity for intelligence-based competition and stimulate rapid growth (Kambil, Eselius and Monteiro, 2000).

Such expectations have triggered substantial public policy attention and investment in the last five years globally which has seen the number of incubators soar worldwide. In the United Kingdom, for example, between 2001 and 2005 the U.K. government established a £75m Incubator Fund and a £50m Innovative Incubators and Clusters Fund as part of its strategy for opportunity and wealth creation (DTI, 2001). There are now over 200 incubators in the U.K. and circa 1,000 in the United States. In China, the growth has been most prolific with more than 20,000 technology firms having been incubated within the last decade from 53 national incubators (Atuahene-Gima and Li, 2004). Incubators are also an important economic development mechanism for the OECD (Nolan, 2003). 
Young firms have limited knowledge and look to the experiences of networked firms to learn and acquire existing knowledge. Incubators extend from this logic but the learning achieved is of an 'exploitative’ and not 'exploratory’ nature. Explorative learning captures creativity, experimentation, play and discovery to create knowledge. Exploitative learning conveys refinement, efficiency and execution (March 1991). Explorative and exploitative learning reflect different capabilities for knowledge production, affect the nature of knowledge produced and the behaviours necessary to create it (Özsomer and Gençtürk, 2003). Explorative learning creates new knowledge with potentially high but uncertain returns. Exploitative learning, drawing on existing knowledge to make full use of what is already known, generates incremental knowledge with moderate but certain and immediate returns (Schulz, 2001). Over time, explorative knowledge is more valuable.

Hite and Hesterly (2001) examined the evolution of firm networks and found that emerging firms persistently exploit current networks of relationships to acquire exploitative knowledge as the value of that knowledge is clear and can be readily applied. This is echoed by Koza and Lewin (1998) who observed the strong tendency for inter-organisational relationships to adopt exploitative learning, rather than exploratory, for similar reasons. Network relations increase the speed of acquiring knowledge that contains little uncertainty, has a known value and can be repeatedly accessed and thus can become 'addictive' to an emerging young firm in possession of poor knowledge reserves.

The network context, and the exploitative learning it facilitates, possesses some key drawbacks. Exploitative learning can be self-reinforcing leading to: over-reliance; decreased variation in knowledge across firms and inside firms; impaired capacity for exploration; efficiency over effectiveness; and, reduced performance in the long run (Kyriakopoulos and Moorman; 2004). Critically, exploitative learning institutionalises its behaviours of search, refinement and efficient execution over time such that it becomes a dominant orientation and 
risks shaping an internal environment that regards its behaviours as the most desirable (March, 1991; cf. Atuahene-Gima and Ko, 2001).

This leads to the second strategic challenge-to maximise gains from EO. An EO captures the decision-making styles, processes and practices that specify how a firm intends to operate and compete (Lumpkin and Dess, 1996). It is commonly configured by risk-taking, innovativeness and proactiveness (Miller, 1983) and represents a bias toward exploration and experimentation. EO reflects many of the antonyms associated with refinement, efficiency and execution implied by exploitative learning and is congruent to the play and discovery dimensions of exploratory learning. EO reflects behaviours such as creative experimentation, proactive discovery, change anticipation and tolerance of the unknown (Lumpkin and Dess, 1996). EO mobilises a firm to generate explorative knowledge that increases internal variety through knowledge richness, which is associated with innovation and superior performance (McGrath, 2001). These behaviours are in sharp contrast to those associated with exploitative learning. An imbalance toward exploitative learning risks creating an internal environment that reinforces its behaviours at the expense of play, discovery and experimentation. If EO proves to be a powerful basis for competitive advantage then this poses serious consequences to emerging young firms already undermined by liabilities of newness. Presently, no study has examined the relationship between exploitative learning and EO and so thus far we do not appreciate the possible consequences of pursuing both.

The relationship between network-based exploitative learning and EO has been ignored which is of concern as, at least at a conceptual level, there appears distinct sources of incompatibility between the two which might jeopardise performance in emerging young firms. The strategic management literature has pushed learning and EO as separate agendas for competitive advantage but what happens if a firm attempts to utilise both? We contend that the EO-performance relationship is non-monotonic and subject to contextual variation; 
variation that might result from a strong exploitative learning orientation being incompatible with a strong EO. We examine whether the degree of exploitative learning in firms has an impact on the EO-performance relationship. We use configuration theory to assess an arrangement of EO to detect whether EO and the way in which it is configured is a reason for high performance. We then examine this same relationship with groups of firms at different levels of exploitative learning to ascertain whether these orientations are at all compatible. Analysis of the level of exploitative learning on a configuration of EO offers a novel examination of the ways in which emerging young firms can secure superior performance.

\section{THEORETICAL DEVELOPMENT}

\section{Incubator Networks and March's Theory of Learning}

Business incubators provide hubs for emerging young firms to network. Typically connected to the incubator is a network of other emerging young 'incubating' firms, on-site business assistance organisations and any other firm brought into the network by incubator management. The networked incubator exposes emerging young firms to a wealth of collaborative opportunities to learn and acquire knowledge (Hansen et al., 2000).

Emerging young firms utilise extensive network relations to acquire knowledge of a known value, which is already articulated and carries certain outcomes (Hite and Hesterly, 2001). They do so because it is easy, requires little resources and the knowledge is readily available and applicable. Incubators build on this point. By providing a readily accessible network, opportunities to acquire established knowledge increase exponentially (Hansen et al., 2000; Kambil et al., 2000). Pursuing such knowledge is an activity known as exploitative learning (March, 1991). Exploratory learning, in contrast, is more directly compatible with EO as it is the product of play, discovery and experimentation, which are behaviours synonymous with our conception of EO as innovative and proactive activity to shape a firm's understanding of the market and its direction (Lumpkin and Dess, 1996). Still, it is highly 
uncertain, erratic in its creation and of ex ante unknown value (March, 1991). Exploitative learning is highly desirable as it rapidly expands the firm's knowledge base at little cost or uncertainty. Yet, firms undertaking such learning risk continuously acquiring merely existing knowledge of no uniqueness and becoming addicted to its certainty. The result would be excessive exploitative routines at the expense of exploration. The challenge of balancing these two different sets of behaviours is one of ambidexterity (O’Reilly and Tushman, 2004).

The certainty and known value of exploitative knowledge means it typically becomes self-reinforcing and leads a firm to progressively implement, consciously or unconsciously, systems and processes that tap this form of knowledge (March, 1991). Since exploitative knowledge is associated with refinement, efficiency and certainty, it sits uncomfortably next to the creativity, experimentation and ambiguity implied by a strong EO. A strong EO requires innovative processes in the firm and if used repeatedly can generate explorative knowledge, which is a key resource in developing unique products to overcome advantages enjoyed by incumbents (Knight and Çavuşgil, 2005). Yet, the certain outcomes resulting from exploitative learning mean it is likely to be preferred over time to the uncertainty of EO. In doing so, emerging firms expose themselves to an additional strategic liability as the value of exploitative learning diminishes severely over time as it lacks uniqueness (Kyriakopoulos and Moorman, 2004). Consequently, examining a configuration of EO needs to be balanced by an understanding of potential contextual factors that might vary its outcomes.

\section{Configuration Theory}

Our research questions are two fold. First, does a robustly configured EO contribute to performance? Second, does the degree of relationship-based exploitative learning vary this effect? We use configuration theory to examine these questions because it allows us to construct profiles of an EO configuration in firms and assess whether it makes a meaningful contribution to performance, a prerequisite to examining our second research question. 
Configuration assessment is used to develop a profile of a set of dimensions across a set of firms. Typically, it is used to develop an 'ideal' profile of a set of dimensions drawing it from a sub-set of 'high-performing' firms within a dataset (Doty, Glick and Huber, 1993; Ketchen, Thomas and Snow, 1993; Vorhies and Morgan, 2003). High-performers are identified based on selected performance criteria. Then, a profile of these firms based on a separate set of dimensions is mapped. In this case, we are interested in the entrepreneurial conditions of high-performing firms, thus, the profile is built from EO dimensions.

Decomposing high performers and identifying the conditions contributing to their exemplary performance allows us to better understand why some firms achieve more than others (Hewett, Roth and Roth, 2003). This method has previously been used to benchmark the marketing capabilities of high-performing firms (Vorhies and Morgan, 2005), assess small firm strategic choice (Ebben and Johnson, 2005) and measure alignment between relational conditions and product performance (Hewett et al., 2003). We identify highperforming firms based on two performance criteria and then use configuration analysis to develop an 'ideal' profile of these firms' EO based on its three most common dimensionsrisk-taking, innovativeness and proactiveness - to examine whether EO is meaningful to high performance. This profile is described as 'ideal' in that the configuration of EO dimensions is drawn from a sub-set of firms in our dataset that are classified as high performers and represents a benchmark of exemplar firms (Vorhies and Morgan, 2005) ${ }^{2}$.

Profiles can be created theoretically (by estimating ‘ideal’ values for dimensions by drawing on an extensive body of extant studies) or empirically (by examining empirical data on high-performing firms) (Ketchen et al., 1993; Vorhies and Morgan, 2003). The 'ideal' profiles could not be precisely specified from theory as the EO literature is not sufficiently

\footnotetext{
${ }^{2}$ We employ cautiously the term 'ideal'. We seek to use accepted terminology associated with configuration theory but stress that these 'ideal' profiles should be considered as benchmarks that are empirically established to represent the group of highest performers within a dataset (Vorhies and Morgan, 2005). Although the term 'ideal' implies a certain degree of precision, it should be viewed instead as a degree of excellence.
} 
mature to enable numerical estimation of its dimensions. Thus, 'ideal' profiles were empirically derived.

Once an 'ideal' benchmark profile has been established, configuration analysis then allows us to examine whether poor 'fit' (or poor alignment) with this profile has an impact on performance by comparing the high-performers against firms outside this group. Poor fit is characterised as ‘profile deviation’ (Doty et al., 1993; Venkatraman, 1989). Deviation ${ }^{3}$ from an 'ideal' profile implies a lack of fit. Profile deviation defines the extent to which the fit among EO dimensions of regular firms differs from that of the 'ideal' (or benchmark) profile drawn from high-performing firms (Vorhies and Morgan, 2003). If EO is meaningful to performance, deviation will result in a negative and significant relationship with performance. Thus, unless EO is meaningful to performance, high performing firms constituting an 'ideal' may be high performers for any number of possible reasons. ${ }^{4}$ If the configuration of EO is irrelevant to a high-performing group, statistical tests would demonstrate a non-significant relationship between deviance and performance. Moreover, a second test to verify whether a correctly configured EO is meaningful to performance is to test deviation in regular-performing firms constituting a 'non-ideal' profile. For EO to be meaningful to performance there must be difference between the 'ideal' profile highperformers and a comparable 'non-ideal' group of regular performers.

\section{Configuration Analysis and EO}

Research into EO purports that risk-taking, innovativeness and proactiveness all provide equal value to the firm and have tended to imply that each dimension should be 'high' but do not quantify this or calibrate a scale to indicate how the dimensions of EO interact with one another (Wiklund and Shepherd, 2003; cf. Lumpkin and Dess, 1996).

\footnotetext{
${ }^{3}$ This is the statistical difference (in Euclidean terms) between a firm's configuration of EO and the 'ideal' profile configuration of EO.

${ }^{4}$ The term 'ideal' is merely theoretical at this stage. It only becomes a true 'ideal' if we demonstrate statistically that the profile of EO drawn from high-performing firms is meaningful to their performance (in terms of deviation) and deviation is non-significant in non-ideal type firms.
} 
Drawn from firms known to have 'superior' performance, we can determine whether EO is a reason for such performance by assessing the impact of deviation, or difference, from this configuration with firms outside the high-performing group. We consider exploitative learning through network-based relationships as a source of variation. The impact of deviation from an 'ideal' EO profile on business performance is examined as well as the impact of deviation when firms are categorised according to their level of exploitative learning activity. This is conceptualised in Figure 1.

\section{INSERT FIGURE 1 ABOUT HERE}

\section{HYPOTHESES}

\section{Entrepreneurial Orientation Fit and Business Performance}

We conceptualise business performance as market performance and response performance due to the implications they hold for competitiveness and survival. Achieving successful market performance by generating strong sales turnover and establishing market share (Homburg and Pflesser, 2000) is pivotal to the success of young firms as they must develop a market presence quickly relative to rivals. Response performance captures the success of a firm in executing adaptations in response to market changes and competitor manoeuvres (Grewal and Tansuhaj, 2001).

EO describes how a firm operates and competes with respect to the bias for pursuing opportunities (Lumpkin and Dess, 1996). Several definitions of EO exist but Miller’s (1983) is most commonly adopted-an entrepreneurial firm is one that engages in innovation, undertakes risk and is proactive in its approach to competition and seizing opportunities. The combination of these three components (risk-taking, innovativeness and proactiveness) reflects the three commonly accepted features of an EO (Barringer and Bluedorn, 1999; Wiklund and Shepherd, 2003). Risk-taking refers to tolerating resource commitment to projects that possess uncertain outcomes or high failure costs and a willingness to break away 
from 'tried-and-true' paths; innovativeness describes a tendency to support and embrace creativity, experimentation, novelty, technological development and deviance from established practice; and, proactiveness relates to a forward looking outlook where firms actively seek out and exploit opportunities to introduce new products, anticipate change and generate first-mover advantages that shape market direction (Lumpkin and Dess, 1996). These dimensions drive exploration within the firm that allow it to reconfigure resources and knowledge into new and better product-market solutions to meet perceived or anticipated change (Atuahene-Gima and Ko, 2001; Bhuian, Menguc and Bell, 2005).

Without an EO, a business would be neither dynamic nor adaptive. Atuahene-Gima and Ko (2001) argue that when the dimensions of EO are arranged correctly, they can trigger experimentation and creativity that encourage new resource combinations that allow the firm to pursue opportunities ahead of rivals and potentially implement frame-breaking activities. There are two ways in which this is achieved. First, EO assists firms to understand the market better and see the market in different ways, facilitating superior offerings to be made which assists the firm to seize market share and attract customers to its products (Slater and Narver, 1995). Second, a fundamental part of the activity entailed by EO is not only to create products ahead of competitors but also to create products ahead of customer recognition.

Risk tolerance in firms requires a combination of constructive risk-taking, exploration and opportunity-seeking behaviour (Lumpkin and Dess, 1996). Research suggests that only under these conditions coupled with a rule-breaking approach to business can risk-taking improve market performance (McGrath, 2001). Innovativeness is often linked to strong market benefits when new products and technologies are commercialised successfully. Proactiveness can lead to strong market performance because the emphasis on 'step-ahead' tactics (Morgan and Strong, 2003) can stimulate superior returns from market leading and shaping behaviour (Wright, Kroll, Pray and Lado, 1995). 
H1(a): The greater the fit between EO dimensions and the 'ideal profile', the greater firms’ market performance.

Concerning response performance, the purpose of EO is to instil an anticipatory capability within the firm to initiate timely, creative and intelligent responses to adapt to changing market conditions and actively seize opportunities. McGrath (2001) found that probing and experimenting are essential if firms are to develop an innovative capacity to achieve effective adaptation to continuously changing conditions. An EO would be essential in this respect given that its dimensions are geared toward discovery of opportunities and threats ahead of competitors, the creation of diversity in the firm's activities to exploit discoveries and create explorative knowledge which can lead to new insight into tackling opportunities and threats. McGrath (2001) further posited that without such entrepreneurial conditions, the risk of managerial oversight to market change increases, which would thus harm the effectiveness of response and thus performance.

Risk-taking typifies a tolerance of the unknown. Firms adopting this feature tolerate the ambiguity of renewal which should influence response performance as it encourages the firm to undertake and implement solutions in the face of uncertain outcomes. Proactiveness is said to be highly associated with superior responsiveness to market signals (Wright et al., 1995) and epitomises an anticipatory capability to identify and actively manage change. Thus, we expect a positive relationship would exist with response performance.

H1(b): The greater the fit between EO dimensions and the 'ideal profile', the greater firms’ response performance.

\section{Exploitative Learning, EO and Firm Performance}

If hypothesis 1 holds true and we expect high-performing firms to possess a wellconfigured EO as a reason for their high performance, those firms will then be proficient in creative and proactive activities. As such, the processes of the firm and the behaviours of its 
people will be geared toward seamless opportunity identification and exploitation with a view to shaping the market environment to the firm's advantage. Such activities however are explorative in nature and, whilst uncertain, can reap significant value to a firm.

For such activities to become and remain a dominant orientation requires them to be repeatedly applied. This cannot happen however in situations where a firm is operating a second orientation whose principles are in contrast to the other. The orientation that will dominate is the one whose behaviours are simple, easily repeated and result in clear outcomes which render immediate benefit. This represents the clash between EO and exploitative learning. The processes and behaviours associated with exploitation are in stark contrast to those associated with EO. Exploitative learning ignores newness and uniqueness and is an activity solely intended to harvest existing knowledge, which carries a known certain outcome, thereby relying on a process of search, collection and assimilation. An EO generates new, unique or explorative knowledge through practices centring on creativity and discovery. Whilst these generate uncertain outcomes, their potential value is far greater than merely exploiting existing knowledge shared across firms. Both orientations are incompatible as each requires a different set of procedures than the other and as returns from exploitation are far more certain than returns from an EO, the likelihood that it becomes a dominant orientation is increased (Kyriakopoulos and Moorman, 2004; Levinthal and March, 1993).

There are two fundamental drivers of this dominance problem. First, the problem is exacerbated by the nature of knowledge acquisition in young firms. Based on liabilities of newness theory, young firms lack business acumen, knowledge of markets and knowledge of methods to compete effectively. This in fact represents the raison d'etre for networked incubators, who provide a network of firms from which a young firm can acquire knowledge rapidly and repeatedly to quickly leverage its weak knowledge base and reduce its knowledge gaps (Hansen et al., 2000; Rice, 2002). Evidence shows that emerging young firms perform 
most of their learning activity through relationships. The lack of depth in their knowledge bases compel them to consciously or unconsciously develop relationships to quickly acquire knowledge that is of proven value and renders immediate and certain benefit (Hite and Hesterly, 2001). In doing so, they learn exploitatively.

The second part of the dominance problem relates to firm design. Firms that engage extensively in exploitative learning risk becoming dysfunctional because they make implicit choices on firm design, processes, behaviours and resource allocations (March, 1991) that are shaped around information processing systems based on a costly and slow process of extensive knowledge search and assimilation (Lant and Mezias, 1990). It follows that strong exploitative learning will result in internal firm conditions to change and strengthen to reflect these activities (March, 1991). Employees will then pursue strategic initiatives that reflect exploitative learning as the chief modus operandi (cf. Atuahene-Gima and Ko, 2001). Mezias and Lant (1994) warn such a design can reduce the impetus for change and discovery, two fundamental principles of EO. Further, the inertia caused by such activity would reduce firms’ capacity to adapt to future challenges and opportunities (He and Wong, 2004) by minimising discovery-led processes in favour of knowledge acquisition-led activities. The firm risks entering a learning trap as it becomes reliant on acquiring knowledge against creating novel insights (Levinthal and March, 1993). Accordingly, this will deleteriously affect efforts to be strongly entrepreneurially oriented.

Because the benefits of exploitative learning are more certain and immediate than EO, managers tend to put more resources into exploitative practices (March, 1991). For highly entrepreneurial firms, the process of gathering and acquiring information might be done out of a sense of obligation rather than as a meaningful practice (Bhuian et al., 2005). But, as systems are implemented to acquire and process exploitative knowledge and resource allocation reinforce it over time (March, 1991), the result would be a rigid and inert system in 
which exploitative learning commands greater resources and presence than EO, which risks degrading performance by reducing the firm’s capacity to generate novel solutions in anticipation of and in response to change.

H2: In firms that exhibit weak exploitative learning (as opposed to those firms exhibiting moderate or strong exploitative learning), the greater the fit between EO dimensions and the 'ideal’ benchmark profile, the greater firms’ (a) market performance and (b) response performance.

\section{RESEARCH METHODOLOGY}

\section{Sample}

Emerging young firms of a high technology nature are the focus of this study. The United Kingdom Business Incubation directory of incubator centres contained firms that satisfied our sampling criteria. Incubators in the U.K. tend to encourage entrepreneurship and learning within firms in an effort to promote performance and typically emphasise collaboration among the firms in their portfolio. Our analysis of this sample source revealed that approximately $73 \%$ of the registered facilities were oriented toward firms which matched our high technology criteria. The young high technology firms located in these facilities reflected such industries as science, bioscience, technology and knowledge-based, engineering, laser engineering and information technology. These firms were random sampled until 1,000 emerging young high technology firms were selected.

\section{Data Generation}

A key informant approach was deemed a methodologically appropriate manner to generate data. The information requirements of the study dictated that the informant be of senior management level. Managing Directors are the chief source of information about strategic processes and are the key source of information about practices, processes and outcomes of the firm, particularly in young firms. A mail survey instrument was used to 
generate data and its design and administration were in line with the Tailored Design Method (Dillman, 2000). A pre-notification letter, questionnaire package and first and second reminders were dispatched respectively to sampling units at specific intervals. A total of 211 eligible responses were received. To test for non-response bias, the Armstrong and Overton (1977) extrapolation method was used. No significant differences were found, at conventional levels $(p=.05)$, between early $(n=110)$ and late $(n=101)$ respondents across the range of measurement scales adopted, indicating non-response bias was not present.

\section{Operationalisation and Measurement}

All items were measured on seven-point scales. Items for EO, learning and market performance were anchored by "Strongly disagree” (1) to "Strongly agree” (7). Response performance items were anchored by "Very poor" (1) to "Excellent” (7). Measures were mostly sourced from previous studies with revision to account for context where needed.

Risk-taking items were obtained from Barringer and Bluedorn (1999), Hult and Ketchen (2001) and Morgan and Strong (2003). Innovativeness items were mostly sourced from Calantone, Çavuşgil and Zhao (2002). Proactiveness items came from Hult and Ketchen (2001) and Morgan and Strong (2003). We found no scales for firms’ network-based exploitative learning activity in the literature so we developed our own. We examined research that have considered the role of exploitative learning in relations (Koza and Lewin, 1998) in addition to work on exploitative learning in general (March, 1991) and on learning in incubators (Hansen et al., 2000; Kambil et al., 2000). Exploitative learning describes learning activity focused on acquiring existing knowledge to be used with the understanding that it already has a known value and outcome. In the context of relations it is acquired through interactions. We sought to capture a relational view of exploitative learning by developing scales based on the exchange of information among firms, bringing participants into projects to inform activities and the extent of learning among firms. Market performance 
scales were informed by Homburg and Pflesser (2000), Morgan and Strong (2003) and Vorhies and Morgan (2003). Response performance items were informed by Krohmer, Homburg and Workman (2002) and Grewal and Tansuhaj (2001).

The questionnaire was subjected to several edits and finally pre-tested through presentation of the scales to expert judges consisting of academic experts, managers and field experts who judged their representativeness and appropriateness. Feedback led to various adjustments and alterations to the items and questionnaire. These tasks were undertaken to ensure adequate face and content validity.

Measures were entered into a single confirmatory factor analysis and following standard practice we eliminated measures which possessed extremely poor factor loading. It was clear that these items did not correspond to the constructs defined and so were removed from the confirmatory model. We believe the number of items contained in the analysis did not exceed the parameters to observations ratio. The final measurement model fits the data well (Table 1) and supports our judgement on performing a single confirmatory model. In each instance, the fit indices, standardised factor loadings and $t$-values were all above accepted levels and within accepted ranges. The composite reliabilities and average variance explained for each construct are presented in Table 2 and are within accepted ranges.

\section{INSERT TABLE 1 ABOUT HERE}

\section{INSERT TABLE 2 ABOUT HERE}

Single source self-report instruments provide the basis for data generation in this study. An artefact of this approach is that common method variance may underlie the data. When developing the research design we were mindful of the Spector and Brannick (1995) protocol for limiting such bias. Consequently, within the survey instrument we: placed the scales in a random order; did not script or suggest any idealised response; adopted non-loaded expressions and neutral wording throughout our measures; reduced the length of the survey 
instrument; and, we provided detailed instructions for questionnaire completion. Following data generation, we examined for common method variance using the Harman one-factor test (Podsakoff and Organ, 1986). Specifying all study variables in a sole factor using confirmatory factor analysis, we examined the fit indices. If common method variance represents problematic error, then a single factor will fit the data well. The results of this analysis reveals that this was not the case $\left(\chi^{2}=1343.64\right.$, D.F. $=135, p=0.00, \mathrm{CFI}=0.58, \mathrm{GFI}=$ $0.56, \mathrm{NNFI}=0.52, \mathrm{RMSEA}=0.22)$. We conclude therefore that common method bias does not appear to be problematic within our data (Podsakoff, MacKenzie, Lee and Podsakoff, 2003).

Firm size and age were used as control variables. Firms of different size and age may exhibit different characteristics which may influence performance. To control for firm size, we asked respondents to detail the approximate number of full-time employees at their firm. To control for firm age, we asked respondents to detail how many years and months the firm had been operating. The natural log form of firm size and age were used.

\section{'Ideal' Profile Method}

Profiles are constructed based on EO dimensions and then drawn from highperforming firms. There are three phases to the development of the 'ideal' benchmark profiles. First, we developed 'ideal' EO profiles from the high-performing firms against which fit (deviation) and its impact on performance could be assessed. Second, we distinguished between firms in our sample as weak, moderate and strong exploitative learners. Third, we developed 'ideal’ EO profiles from the high-performers of each learning group—weak exploitative learners $(n=69)$; moderate exploitative learners $(n=102)$ and strong exploitative learners $(n=33)$ — to assess the effect of fit at different levels of learning.

Following techniques consistent with prior studies adopting this method (Hewett et al., 2003; Vorhies and Morgan, 2003), we identified the highest performing firms based on our performance criteria from all of those sampled. We then created the first set of 'ideal' 
benchmark profiles of EO, using the mean scores on each EO dimension of the top performers in both market and response performance to form the 'ideal' profiles to test H1a and H1b. Recall that it is 'ideal' only because it is drawn from high-performers. To determine if a configured EO is a reason for high performance, we must assess whether deviation from this ‘ideal’ (by comparing to standard-performing firms) results in a significant difference. Only at that stage can we determine whether EO is of any value to high-performing firms.

As can be seen in the Appendices, on a measurement scale of 1 (very low) to 7 (very strong), the EO dimensions constructing the 'ideal' benchmark profiles on average are valued around 6. These figures imply that risk-taking, innovativeness and proactiveness, although independent, are also interdependent. In no case is a relatively strong value matched with a weak value. This indicates that firms should organise their activities around strong creativity mechanisms, with an emphasis on proactive environmental scanning and change anticipation, and balance this with a tolerance of risk which accounts for making reasonable decisions to mitigate negative risk. Recent research supports this characterisation (Bhuian et al., 2005) despite contrasting the more bullish characterisations of some predecessors (Miller, 1983).

We then identified the highest performers at each level of learning on each performance dimension and calibrated their EO scores to establish the set of 'ideal' EO profiles for each learning group along both types of performance to test H2a and H2b. To examine $\mathrm{H} 1$ and $\mathrm{H} 2$, the distance from the 'ideal' profiles of the remaining firms outside of the highest performers was calculated to form a profile deviation score reflecting the degree to which the EO profile of each firm was similar to that of the first 'ideal' EO profile (H1) and the set of 'ideal' EO profiles for each level of learning (H2).

The first set of profile deviation scores were entered into a regression model with market and response performance along with the control variables to test H1a and H1b respectively, and, for $\mathrm{H} 2 \mathrm{a}$ and $\mathrm{H} 2 \mathrm{~b}$, the sets of profile deviation scores for firms at each level 
of learning were similarly regressed. To assess the strength of our hypothesis tests and for the results to be meaningful, we must compare regression models containing deviation from the ‘ideal’ profile drawn from high performers with models containing deviation from an alternative random 'non-ideal’ profile drawn from regular performers (Vorhies and Morgan, 2003). Hence, we repeated the process of developing 'ideal' profiles to form 'non-ideal' profiles by randomly selecting a number of firms equivalent to the same number of firms in each 'ideal' profile. The 'non-ideal' profile deviations were then entered into the regression models in place of the 'ideal’ profile scores to enable comparison and rule out the possibility that any random EO profile would contribute to higher performance. For the hypotheses to be supported, the results should show that deviation from the 'ideal' EO profile is negatively and significantly related to both forms of performance and that deviation from 'non-ideal' profiles is statistically insignificant. This would provide support as greater deviation from the 'ideal' reflects lower fit which, as hypothesised, should lower performance. The results for H1a and H1b are shown in Table 3 whilst the results for H2a and H2b are presented in Table 4.

\section{INSERT TABLE 3 ABOUT HERE}

\section{INSERT TABLE 4 ABOUT HERE}

\section{RESULTS}

Table 3 shows that our hypothesis testing results provide full support for H1a and H1b, which predicts the greater the fit between a firm's EO profile and that of the 'ideal' benchmark EO profile, the greater its market performance and response performance. This is evidenced by the regression models which show statistically significant negative relationships between deviation from the 'ideal' profile and both market performance $(\beta=-0.23, p<0.01)$ and response performance $(\beta=-0.44, p<0.01)$. The regression models for the non-ideal profiles indicate no significant relationship between deviation from the 'non-ideal' EO profile and either type of performance. We can so deduce that deviation from an 'ideal' EO profile 
harms firm performance. Thus, EO is a reason for exemplary performance in high-performing firms and so managers should carefully configure their firms' EO to improve performance.

Table 4 reports the results of hypothesis tests for H2a and H2b. The results provide full support for H2a, which predicts that only firms exhibiting weak exploitative learning will experience greater market performance when there is close fit between its EO dimensions and the 'ideal’ EO profile. The market performance regression models report a statistically significant negative relationship for deviation from the 'ideal' benchmark profile of EO for weak exploitative learning $(\beta=-0.37, p<0.01)$ and non-significant relationships for moderate and strong exploitative learning. This is further supported by the non-ideal regression models which indicate no significant relationship exists between non-ideal EO profile deviation and market performance in any of the learning groups. We conclude that highly entrepreneurially oriented firms closely fitted to the ‘ideal’ profile experience significant improvements in market performance when they are weak exploitative learners but experience no such gain when they are moderate or strong exploitative learners. Strong exploitative learning appears not to be beneficial when combined with a carefully configured EO.

H2b predicted that in firms exhibiting weak exploitative learning (compared to firms exhibiting moderate or strong exploitative learning), the greater the fit between EO dimensions and the 'ideal' EO profile, the greater the firm's response performance. The results offer support for H2b. The response performance regression models report statistically significant negative relationships for deviation from the 'ideal' EO profile for weak exploitative learning $(\beta=-0.36, p<0.01)$ and moderate exploitative learning $(\beta=-0.39$, $p<0.01$ ) whilst a non-significant relationship is found for strong exploitative learning. Whilst these results are varied, they do support our hypothesis that for firms which exhibit weak exploitative learning, greater fit with the ‘ideal’ EO profile has a positive performance effect but strong exploitative learning does not generate such rewards. Further credence is provided 
by the non-ideal regression models which indicate non-significant relationships between deviation from the non-ideal profile and response performance in each learning group. We can surmise therefore that EO can be a powerful contributor to firm performance but the effect is diminished if a firm also has a strong exploitative learning orientation.

\section{DISCUSSION AND IMPLICATIONS}

This study sought to ascertain whether EO explains high performance in firms and sought to examine the influence exploitative learning can have on entrepreneurially driven firms. We adopted the networked incubator as a context for this study. We applied configuration analysis to determine whether the alignment of a firm's EO with an 'ideal' benchmark profile (or configuration) of EO drawn from a set of high-performing firms influences its relationship with firm performance. We then compared the configuration of EO of all other firms to this 'ideal' profile and tested whether deviation undermined performance. We conclude that EO explains high performance in the exemplar firms and explains mediocre performance in regular firms. We further examined whether this relationship changed if firms exhibited weak, moderate or strong levels of learning. Using March’s (1991) theory of exploitative learning and applying it to relationships, the principal knowledge acquisition mechanism in emerging firms, we discover that the level of such learning changes the nature of this relationship. Organising EO activities such that they fit closely with the 'ideal' EO profile has the most impact when firms exhibit weak exploitative learning. Those firms with strong exploitative learning accrued no performance benefit. Inconsistencies in the EOperformance relationship, therefore, might be a product of poor configuration or a dominant exploitative learning orientation. Moreover, an incubation strategy focused on sharing and leveraging existing knowledge appears flawed given our results. Further, an exploitative approach to learning introduces a trap whereby firms obtain short term knowledge gain but harms the contribution an EO can make to performance and advantage in the longer term. 


\section{Implications for Managers of Emerging Young Firms}

EO can be beneficial for firm performance when it is appropriately configured and aligned. However, it is not always straightforward for managers to appreciate where weaknesses might lie. Managers of emerging young firms should therefore benchmark their firms' scores on EO dimensions to ascertain their fit to the 'ideal' benchmark identified herein to assess how and where performance might be improved. By tailoring the configuration of EO, managers can accrue a clear performance benefit for their firms according to our findings. Although EO dimensions can vary independently (Lumpkin and Dess, 1996), they should be adjusted independently only to achieve an interrelated configuration. Through benchmarking, weaknesses in configuration can be isolated and managers can undertake change to one or more dimension.

Managers should also undertake a diagnosis before instigating changes to their EO activities. This study finds that the level of exploitative learning influences the performance repercussions of EO. Managers should examine their firms’ exploitative learning activities in conjunction with their benchmarking activities to diagnose where faults in performance might lie. Diagnosis is needed to isolate whether mediocre performance is a symptom of failure in the EO fit or exploitative learning dominating firm activity relative to EO. This is important as the secure and immediate outcomes available through exploitative learning can blind firms to the longer term value of EO, which is more exploratory but uncertain in its outcomes. Mangers must check the processes of the firm and employees' behaviour to ensure exploitative learning is not dominant. Regular diagnosis will be necessary to ensure exploitative learning activity does not become a dominant orientation, as that would steer the firm to make implicit choices on firm design that would further embed the activity at the expense of EO (March, 1991). Managers must be willing to challenge the learning orthodoxy and focus on exploratory learning via an EO. 
We caution firms against an exploitative learning orientation and instead advocate weak levels of exploitative learning in favour of more entrepreneurial and exploratory learning from experimentation and discovery (to which EO is suitably geared). This implication complements recent studies that have placed caveats on learning. For example, Haas and Hansen (2005) found that acquiring existing knowledge can undermine performance as opposed to knowledge that is created internally. Nonaka and Takeuchi (1995) similarly argue that knowledge intake is no substitute to entrepreneurially created knowledge when pursing innovation. Some degree of exploitative learning through relationships is undoubtedly necessary to acquire basic information but managers must be careful that it does not become a dominant orientation as otherwise it will harm performance by weakening the effect an EO can have. Firms should seek ambidexterity through a balance of exploitative learning and exploratory means, such as EO, since, at weak levels, our results show that exploitative learning complements EO.

An appropriate blend of EO dimensions configured to stimulate high performance must be united with a level of exploitative learning that strategically reinforces the desired outcome. An approach to learning where the acquisition of established knowledge dominates learning activity could lead to a state where knowledge quantity becomes desirable over and above its entrepreneurial creation. This is not a suitable programme for an emerging young firm and, given the fact such learning can be self-reinforcing, emerging young firms might make an unintended strategic decision to destroy value, putting at risk sustainability. EO is one strategy to combat this risk but requires coordination among a number of organisational components. Weak exploitative learning appears to be desirable because it limits the number of routines and procedures to be established, preventing self-reinforcement which would otherwise minimise the impetus for change (Lant and Mezias, 1990; Mezias and Lant, 1994). Implications for Incubator Managers and Public Policymakers 
Emerging young firms acquire their knowledge and perform their learning mostly through network relations (Hite and Hesterly, 2001) and this learning takes the exploitative form. Such learning forms the logic underpinning incubators (Hansen et al., 2000; Kambil et al., 2000) but this is a questionable strategy since our findings show strong exploitative learning activity undermines the effect EO can have on market and response performance. An incubation strategy based exclusively on exploitative learning is therefore flawed.

Incubator managers must reassess how emerging young firms can gain from incubation. We recommend a strategy proposed by Rice (2002) that firms co-produce knowledge by partnering only to pursue new projects rather than simply to gain knowledge or experience from others. Incubator managers should help coordinate such linkages to ensure firms learn exploratively not exploitatively. Public policymakers should consider carefully how they evaluate the longer term success of incubation projects given that incubating firms may perform poorly because their lack of, or poorly configured, EO or a dominant exploitative learning orientation. These are not easily detectable and thus the evaluation of incubator projects will require much closer scrutiny of the incubating firms themselves.

Ambidexterity, a feature incubating firms should strive for (i.e. achieving a balance between EO and exploitative learning such that they become ambidextrous at using both), raises an interesting issue in that intervention by policymakers to encourage firms to share knowledge is suboptimal over time as it is no more than exploitative learning and leads to firms becoming symmetrical in knowledge. Performance advantage according to our findings comes from the entrepreneurial discovery of unique knowledge. Policymakers must be wary of interventionist policies that risk firms embedding exploitative learning practices above EO.

\section{CONCLUSIONS, LIMITATIONS AND FUTURE RESEARCH}

We draw several conclusions but these are tempered by some limitations. First, although our findings are generalisable to young high technology firms, they may not be 
readily applicable to different populations, such as incumbent firms. Future research would therefore benefit from empirically examining our findings in different populations to establish whether they represent a component of a broader phenomenon. Second, when performing configuration analysis, longitudinal data is often considered desirable. However, the use of a cross-sectional design is equally plausible and valid having been used in several other studies (Hewett et al., 2003; Vorhies and Morgan, 2003, 2005). Longitudinal data would have been preferable to examine changes in the configuration over time, but, given that we studied emerging young firms and given some tradeoffs in research design, a crosssectional approach was the most suitable design. Third, we appreciate that the concept of an 'ideal' might sit uncomfortably in an era of change. Nevertheless, the profile presented here can serve as a valuable benchmark for emerging young firms to use to assess their EO and aid in reconfiguring their EO activities with the confidence that performance benefits will accrue.

Configuration assessment can be a valuable tool to understand how and why EO might influence performance. Inconsistencies in the EO-performance relationship can be explained by configuration theories to an extent, yet, we advocate future research into possible mediators and moderators. Future studies into the EO-performance relationship must transcend the direct relationship to explain contradictory findings rather than merely add to the 'good versus bad' debate. Our study provides a step in that direction and follows others in the marketing (Atuahene-Gima and Ko, 2001; Bhuian et al., 2005) and strategy (Wiklund and Shepherd, 2003) traditions in that respect.

Exploitative learning, at least from a relational perspective, is shown to be a strategy with potentially damaging consequences. Indeed, its consequences are so far poorly understood. Some exploitative learning will always be necessary and we do not dispute this. We found that weak exploitative learning complements a configured and aligned EO. However, we caution that such learning, if it becomes a dominant behaviour, can reduce the 
impact of EO on performance and risks becoming self-reinforcing over time. In that regard, future research might consider Winter's (2000) suggestion of a 'satisficing' principle in organisational learning. Our findings indicate that such an approach may well be a worthwhile strategy. In 'satisficing', firms seek existing information only to the extent that it satisfies the need for which it was sought. The thrust of Winter's (2000) argument is that organisational learning should be purposeful and not a process of information harvesting. Firms can easily fall into a 'learning trap' caused by the short-term positive feedback associated with exploitation (Levinthal and March, 1993) which can lead to firms’ specialising in inferior routines (Kyriakopoulos and Moorman, 2004) at the expense of more uncertain exploratory ones such as EO. This to an extent is supported by our findings.

Research efforts should also examine the ambidexterity hypothesis (He and Wong, 2004) to identify what balance is needed between exploitation and exploratory activities and how this balance can be achieved. Also, importantly, incubation research needs to re-evaluate its basis for value creation. Work by Rice (2002) suggests that proactively identifying ways for firms to collaborate on new initiatives might be a way forward. Incubation research should look at how to generate ambidextrous learning in emerging firms that is valuable and self-sustaining over time. A longer-term view of incubating firms is needed rather than a short-termist one that places fast venturing above longer-term potential.

Our findings also hold significance for research into market orientation given its emphasis on knowledge acquisition and exploitation. Recent studies have found the relationship between EO and market orientation to be complex and tenuous (Atuahene-Gima and Ko, 2001; Bhuian et al., 2005). EO ought to benefit market orientation since it orients the firm toward intelligent proactive management of its markets. Research is still in its infancy but given its exploitative learning features, more research is needed. It is clear that more research is required into the complex phenomena of learning, EO and incubation. 


\section{REFERENCES}

Armstrong, J.S. and T.S. Overton (1977), 'Estimating Non-Response Bias in Mail Surveys', Journal of Marketing Research, 14, pp.396-402.

Atuahene-Gima, K. and A. Ko (2001), 'An Empirical Investigation of the Effect of Market Orientation and Entrepreneurship Orientation Alignment on Product Innovation', Organisation Science, 12(1), pp.54-74.

and H. Li (2004), 'New Product Decision Comprehensiveness and Performance in Chinese Technology-based New Ventures’, Academy of Management Journal, 47, pp.583-597.

Barringer, B.R. and A.C. Bluedorn (1999), 'The Relationship between Corporate Entrepreneurship and Strategic Management’, Strategic Management Journal, 20, pp.421-444.

Bhuian, S.N., B. Menguc and S.J. Bell (2005), 'Just Entrepreneurial Enough: The Moderating Effect of Entrepreneurship on the Relationship between Market Orientation and Performance', Journal of Business Research, 58, pp.9-17.

Bøllingtoft, A. and J.P. Ulhøi (2005), 'The Networked Business Incubator-Leveraging Entrepreneurial Agency?', Journal of Business Venturing, 20(2), pp. 265-290.

Calantone, R.J., S.T. Çavuşgil and Y. Zhao (2002), 'Learning Orientation, Firm Innovation Capability and Firm Performance’, Industrial Marketing Management, 31, pp.515-524.

Covin, J.G. and D.P. Slevin (1989), 'Strategic Management of Small Firms in Hostile and Benign Environments’. Strategic Management Journal, 10, pp.75-87.

Dillman, D.A. (2000). Mail and Internet Surveys: The Tailored Design Method, John Wiley \& Sons, New York.

Doty, D.H., W.H. Glick and G.P. Huber (1993), 'Fit, Equifinality and Organisational Effectiveness: A Test of Two Configurational Theories', Academy of Management Journal, 30, pp.1196-1250.

DTI (2001). The Government's Expenditure Plans 2001-02 to 2003-04 and Main Estimates 2001-02, Cm 5112, The Stationery Office, London.

Ebben, J.J. and A.C. Johnson (2005). 'Efficiency, Flexibility, or Both? Evidence Linking Strategy to Performance in Small Firms', Strategic Management Journal, 26, pp.12491259.

Grewal, R. and P. Tansuhaj (2001), 'Building Organisational Capabilities for Managing Economic Crisis: The Role of Market Orientation and Strategic Flexibility’, Journal of Marketing, 65(April), pp.67-80.

Hansen, M.T., H.W. Chesbrough, N. Nohria and D.N. Sull (2000), 'Networked Incubators: Hothouses of the New Economy', Harvard Business Review, 78(5), pp.74-84. 
He, Z.-L. and P.-K. Wong (2004), 'Exploration vs. Exploitation: An Empirical test of the Ambidexterity Hypothesis’, Organisation Science, 15(4), pp.481-494.

Hewett, K., M.S. Roth and K. Roth (2003), 'Conditions Influencing Headquarters and Foreign Subsidiary Roles in Marketing Activities and their Effect on Performance', Journal of International Business Studies, 34, pp.567-585.

Hite, J.M. and W.S. Hesterly (2001), 'The Evolution of Firm Networks: From Emergence to Early Growth of the Firm’, Strategic Management Journal, 22, pp.275-286.

Homburg, C. and C. Pflesser (2000), ‘A Multiple-Layer Model of Market-Oriented Organisational Culture: Measurement Issues and Performance Outcomes', Journal of Marketing Research, 37(4), pp.449-462.

Hult, G.T.M. and D.J. Ketchen (2001), 'Does Market Orientation Matter? A Test of the Relationship between Positional Advantage and Performance', Strategic Management Journal, 22, pp.899-906.

Kambil, A., E.D. Eselius and K.A. Monteiro (2000), 'Fast Venturing: The Quick Way to Start Web Businesses’, Sloan Management Review, 41(4), pp.55-67.

Ketchen, D.J., J.B. Thomas and C.C Snow (1993), 'Organisational Configurations and Performance: A Comparison of Theoretical Approaches', Academy of Management Journal, 36, pp.1278-1313.

Knight, G.A. and S.T. Çavuşgil (2005), 'Innovation, Organisational Capabilities, and the Born-Global Firm’, Journal of International Business Studies, 35, pp.121-141.

Koza, M.P. and A.Y. Lewin (1998), 'The Co-evolution of Strategic Alliances', Organisation Science, 9(3), pp.255-264.

Krohmer, H., C. Homburg and J.P. Workman (2002), 'Should Marketing be CrossFunctional? Conceptual Development and International Empirical Evidence', Journal of Business Research, 55, pp.451-465.

Kyriakopoulos, K. and C. Moorman (2004), 'Tradeoffs in Marketing Exploitation and Exploration Strategies: The Overlooked Role of Market Orientation', International Journal of Research in Marketing, 21, pp.219-240.

Lant, T.K. and S.J. Mezias (1990), 'Managing Discontinuous Change: A Simulation Study of Organisational Learning and Entrepreneurship’, Strategic Management Journal, 11(Summer Special Issue), pp.147-179.

Levinthal, D.A. and J.G. March (1993), 'The Myopia of Learning', Strategic Management Journal, 14(Winter Special Issue), pp.95-112.

Lumpkin, G.T. and G.G. Dess (1996), 'Clarifying the Entrepreneurial Orientation Construct and Linking it to Performance’, Academy of Management Review, 21, pp.135-172. 
March, J.G. (1991), 'Exploration and Exploitation in Organisational Learning', Organisation Science, 2(1), pp.71-97.

McGrath, R.G. (2001), 'Exploratory Learning, Innovative Capacity and Managerial Oversight', Academy of Management Journal, 44, pp.118-131.

Mezias, S.J. and T.K. Lant (1994), 'Mimetic Learning and the Evolution of Organisational Populations', in J.A.C. Baum and J.V. Singh, Eds., Evolutionary Dynamics of Organisations, Oxford University Press, New York, pp.179-193.

Miller, D. (1983), 'The Correlates of Entrepreneurship in Three Types of Firms', Management Science, 29, pp.770-791.

Morgan, R.E. and C.A. Strong (2003), 'Business Performance and Dimensions of Strategic Orientation’, Journal of Business Research, 56, pp.163-176.

Nolan, A. (2003), 'Public Policy on Business Incubators: An OECD Perspective', International Journal of Entrepreneurship and Innovation Management, 3(1/2), pp.22-30.

Nonaka, I. and H. Takeuchi (1995). The Knowledge-Creating Company: How Japanese Companies Create the Dynamics of Innovation, Oxford University Press, New York.

O’Reilly, C., III and M.L. Tushman (2004), 'The Ambidextrous Organisation’, Harvard Business Review, 82(April), pp.74-81.

Özsomer, A. and E. Gençtürk (2003), 'A Resource-based Model of Market Learning in the Subsidiary: The Capabilities of Exploration and Exploitation', Journal of International Marketing, 11(3), pp.1-29.

Podsakoff, P. M. and D. W. Organ (1986). 'Self-Reports in Organisational Research: Problems and Prospects’, Journal of Management, 12(4), pp.531-44.

S.B. MacKenzie, J-Y Lee and N.P. Podsakoff (2003), 'Common Method Biases in Behavioural Research: A Critical Review of the Literature and Recommended Remedies', Journal of Applied Psychology, 88(5), pp.879-903.

Rice, M.P. (2002), 'Co-Production of Business Assistance in Business Incubators: An Exploratory Study’, Journal of Business Venturing, 17(2), pp.163-187.

Schulz, M. (2001), 'The Uncertain Relevance of Newness: Organisational Learning and Knowledge Flows', Academy of Management Journal, 44, pp.661-681.

Slater, S.F. and J.C. Narver (1995), 'Market Orientation and the Learning Organisation', Journal of Marketing, 59(July), pp.63-74.

Spector, P. E. and M. T. Brannick (1995). 'The Nature and Effects of Method Variance in Organisational Research.’ In C.L. Cooper and I.T. Robertson (Eds.), International Review of Industrial and Organisational Psychology, 10, Wiley: Chichester, pp.249-74. 
Venkatraman, N. (1989), 'The Concept of Fit in Strategy Research: Toward Verbal and Statistical Correspondence', Academy of Management Review, 14(3), pp.423-444.

Vorhies, D.W. and N.A. Morgan (2003), 'A Configuration Theory Assessment of Marketing Organisation Fit with Business Strategy and its Relationship with Marketing Performance', Journal of Marketing, 67(January), pp.100-115.

and ------------- (2005), 'Benchmarking Marketing Capabilities for Sustainable Competitive Advantage’, Journal of Marketing, 69(January), pp.80-94.

Wiklund, J. and D. Shepherd (2003), ‘Knowledge-based Resources, Entrepreneurial Orientation and the Performance of Small and Medium-sized Businesses'. Strategic Management Journal, 24, pp.1307-1314.

Winter, S. (2000), 'The Satisficing Principle in Capability Learning’, Strategic Management Journal, 21, pp.981-996.

Wright, P., M. Kroll, B. Pray, and A. Lado (1995), 'Strategic Orientations, Competitive Advantage and Business Performance’, Journal of Business Research, 33, pp.143-151.

Yli-Renko, H., E. Autio and H.J. Sapienza (2001), 'Social Capital, Knowledge Acquisition, and Knowledge Exploitation in Young Technology-based Firms’, Strategic Management Journal, 22, pp.587-613. 
APPENDIX 1

Ideal and Non-Ideal Entrepreneurial Orientation Profile Mean and Standard Deviation Scores

\begin{tabular}{|c|c|c|c|c|}
\hline \multirow{2}{*}{$\begin{array}{l}\text { Ideal Entrepreneurial Orientation } \\
\text { Characteristics }\end{array}$} & \multicolumn{2}{|c|}{ Market Performance } & \multicolumn{2}{|c|}{ Response Performance } \\
\hline & Mean & Standard Deviation & Mean & Standard Deviation \\
\hline Risk Taking & 5.87 & .98 & 6.00 & .71 \\
\hline Innovativeness & 5.54 & .93 & 6.00 & .64 \\
\hline Proactiveness & 6.31 & .94 & 6.00 & 1.02 \\
\hline \multicolumn{5}{|l|}{$\begin{array}{l}\text { Non-Ideal Entrepreneurial } \\
\text { Orientation Characteristics }\end{array}$} \\
\hline Risk Taking & 5.33 & .94 & 5.17 & 1.20 \\
\hline Innovativeness & 5.17 & 1.22 & 5.53 & 1.10 \\
\hline Proactiveness & 5.10 & 1.44 & 5.47 & 1.42 \\
\hline
\end{tabular}


APPENDIX 2

Ideal and Non-Ideal Entrepreneurial Orientation Profile Mean and Standard Deviation Scores by Level of Exploitative Learning

\begin{tabular}{|c|c|c|c|c|}
\hline \multirow{2}{*}{$\begin{array}{l}\text { Ideal Entrepreneurial Orientation } \\
\text { Characteristics }\end{array}$} & \multicolumn{2}{|c|}{ Market Performance } & \multicolumn{2}{|c|}{ Response Performance } \\
\hline & Mean & Standard Deviation & Mean & Standard Deviation \\
\hline \multicolumn{5}{|l|}{ Weak Learners } \\
\hline Risk Taking & 6.05 & .83 & 6.17 & .79 \\
\hline Innovativeness & 5.29 & 1.17 & 6.25 & .50 \\
\hline Proactiveness & 6.63 & .33 & 6.42 & .69 \\
\hline \multicolumn{5}{|l|}{ Moderate Learners } \\
\hline Risk Taking & 5.56 & .90 & 5.78 & .64 \\
\hline Innovativeness & 5.80 & .97 & 5.84 & .60 \\
\hline Proactiveness & 6.09 & .88 & 5.98 & .74 \\
\hline \multicolumn{5}{|l|}{ Strong Learners } \\
\hline Risk Taking & 6.00 & 1.00 & 6.53 & .51 \\
\hline Innovativeness & 5.89 & .84 & 6.40 & .43 \\
\hline Proactiveness & 6.00 & 1.20 & 6.67 & .47 \\
\hline \multicolumn{5}{|l|}{ Non-Ideal Entrepreneurial } \\
\hline \multicolumn{5}{|l|}{ Orientation Characteristics } \\
\hline \multicolumn{5}{|l|}{ Weak Learners } \\
\hline Risk Taking & 5.29 & 1.01 & 5.25 & .63 \\
\hline Innovativeness & 5.42 & .75 & 5.08 & 1.42 \\
\hline Proactiveness & 5.15 & 1.12 & 4.83 & .88 \\
\hline \multicolumn{5}{|l|}{ Moderate Learners } \\
\hline Risk Taking & 5.36 & .97 & 5.04 & 1.04 \\
\hline Innovativeness & 5.78 & .65 & 5.16 & 1.25 \\
\hline Proactiveness & 5.64 & .99 & 5.14 & 1.16 \\
\hline \multicolumn{5}{|l|}{ Strong Learners } \\
\hline Risk Taking & 5.44 & .69 & 5.73 & .49 \\
\hline Innovativeness & 6.22 & .77 & 5.47 & .61 \\
\hline Proactiveness & 6.00 & .88 & 5.33 & .94 \\
\hline
\end{tabular}


TABLE 1

Confirmatory Factor Analysis Results for the Entrepreneurial Orientation, Exploitative Learning and Performance Measures

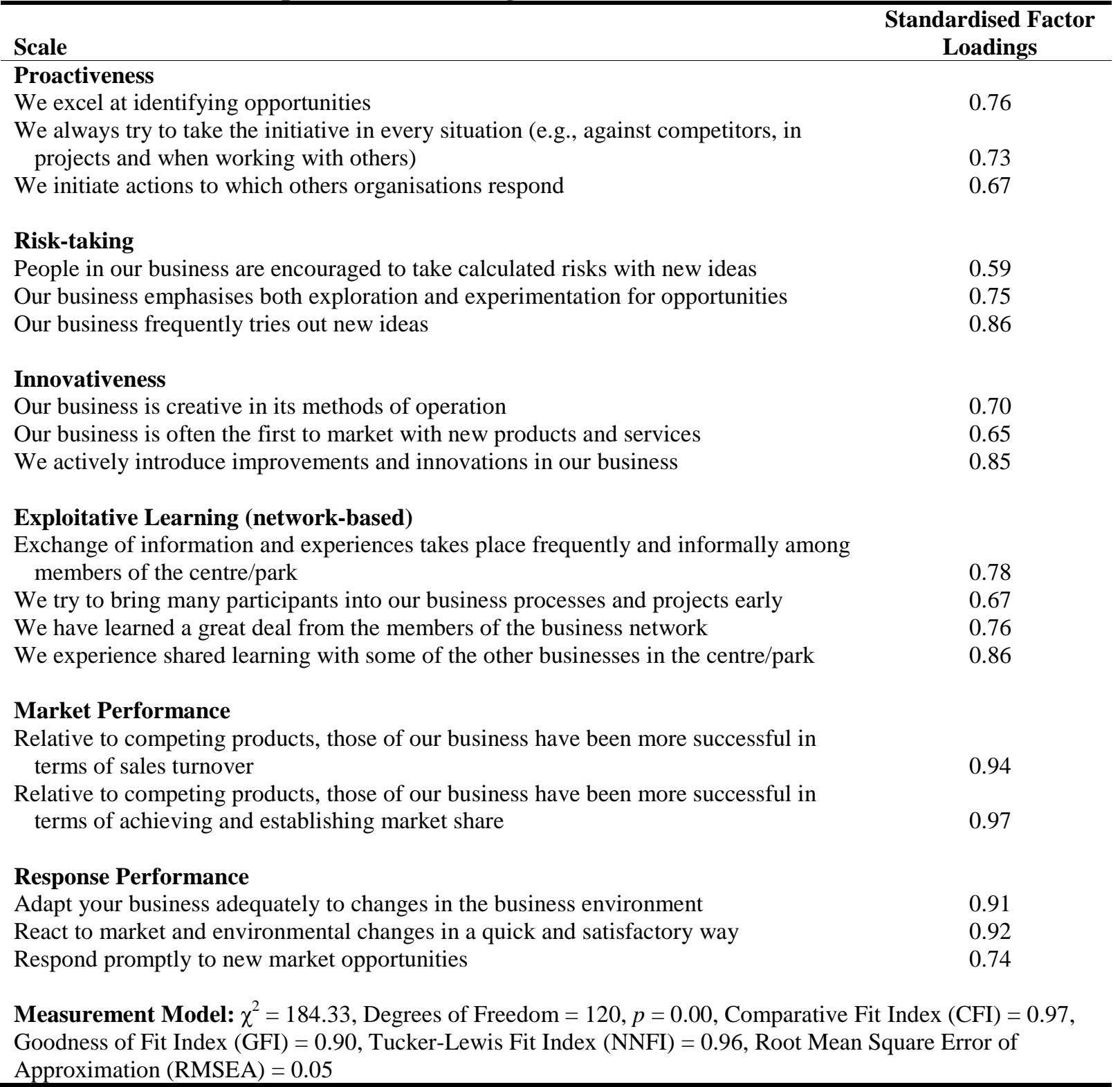


TABLE 2

Construct Means, Composite Reliabilities, Average Variance Explained and Inter-correlations

\begin{tabular}{|c|c|c|c|c|c|c|c|c|c|c|}
\hline & & Mean & $\begin{array}{l}\text { Standard } \\
\text { Deviation }\end{array}$ & $\begin{array}{l}\text { Average Variance } \\
\text { Explained }\end{array}$ & X1. & $\mathrm{X} 2$. & X3. & X4. & X5. & X6. \\
\hline X1. & Proactiveness & 5.33 & .94 & .52 & .76 & & & & & \\
\hline X2. & Risk-taking & 5.37 & .99 & .56 & $.38 * *$ & .79 & & & & \\
\hline X3. & Innovativeness & 5.45 & 1.10 & .55 & $.44 * *$ & $.55^{* *}$ & .79 & & & \\
\hline X4. & Exploitative Learning & 2.89 & 1.36 & .59 & $.17 *$ & $.18^{* *}$ & .07 & .85 & & \\
\hline X5. & Market performance & 4.31 & 1.41 & .92 & $.28 * *$ & .06 & $.27 * *$ & -.12 & .96 & \\
\hline X6. & Response performance & 5.42 & .94 & .69 & $.52 * *$ & $.33^{* *}$ & $.32 * *$ & .03 & $.41^{* *}$ & .87 \\
\hline
\end{tabular}

$* * p<0.01 ; * p<0.05$

Notes: Composite reliabilities (CR) are shown on the correlation matrix diagonal in italic.

TABLE 3

Entrepreneurial Orientation Fit and Performance Regression Models

\begin{tabular}{|c|c|c|c|c|}
\hline \multirow{2}{*}{$\begin{array}{l}\text { Independent } \\
\text { Variables } \\
\end{array}$} & \multicolumn{4}{|c|}{ Dependent Variable } \\
\hline & \multicolumn{2}{|c|}{ Market Performance } & \multicolumn{2}{|c|}{ Response Performance } \\
\hline Profile deviation & $-.23 * *$ & .01 & $-.44 * *$ & -.09 \\
\hline Firm size (log) & $.20^{*}$ & $.24 * *$ & .09 & .00 \\
\hline$R^{2}$ & .10 & .08 & .21 & .03 \\
\hline$F$-value & $6.88^{* *}$ & $5.20 * *$ & $16.37 * *$ & 1.84 \\
\hline
\end{tabular}

${ }^{* *} p<0.01 ;{ }^{*} p<0.05$ 
TABLE 4

Entrepreneurial Orientation Fit with Exploitative Learning and Performance Regression Models

\begin{tabular}{|c|c|c|c|c|}
\hline \multirow[b]{3}{*}{ Independent Variables } & \multicolumn{4}{|c|}{ Dependent Variable } \\
\hline & \multicolumn{2}{|c|}{ Market Performance } & \multicolumn{2}{|c|}{ Response Performance } \\
\hline & Ideal Profile Models & $\begin{array}{c}\text { Non-Ideal } \\
\text { Models }\end{array}$ & Ideal Profile Models & $\begin{array}{c}\text { Non-Ideal } \\
\text { Models }\end{array}$ \\
\hline \multicolumn{5}{|l|}{ Weak Learners } \\
\hline Profile deviation & $-.37 * *$ & -.12 & $-.36 * *$ & .06 \\
\hline Firm size (log) & $.35^{*}$ & $.28 *$ & .09 & .01 \\
\hline$R^{2}$ & .23 & .11 & .15 & .01 \\
\hline$F$-value & $5.37 * *$ & 2.45 & $3.65 *$ & .22 \\
\hline \multicolumn{5}{|l|}{ Moderate Learners } \\
\hline Profile deviation & -.15 & -.11 & $-.39 * *$ & -.00 \\
\hline Firm size (log) & .04 & .22 & .06 & .12 \\
\hline Firm age (log) & .16 & .05 & .04 & -.19 \\
\hline$R^{2}$ & .04 & .08 & .15 & .03 \\
\hline$F$-value & .95 & 2.44 & $3.82 *$ & .60 \\
\hline \multicolumn{5}{|l|}{ Strong Learners } \\
\hline Profile deviation & -.25 & -.12 & -.37 & .25 \\
\hline Firm size (log) & .24 & $.38 *$ & -.12 & .05 \\
\hline Firm age (log) & -.12 & -.22 & .05 & -.26 \\
\hline$R^{2}$ & .12 & .17 & .15 & .09 \\
\hline$F$-value & 1.16 & 1.74 & 1.38 & .81 \\
\hline
\end{tabular}

${ }^{* *} p<0.01 ;{ }^{*} p<0.05$ 


\section{FIGURE 1}

Entrepreneurial Orientation Fit with Entrepreneurial Strategy and its Relationship with Business Performance

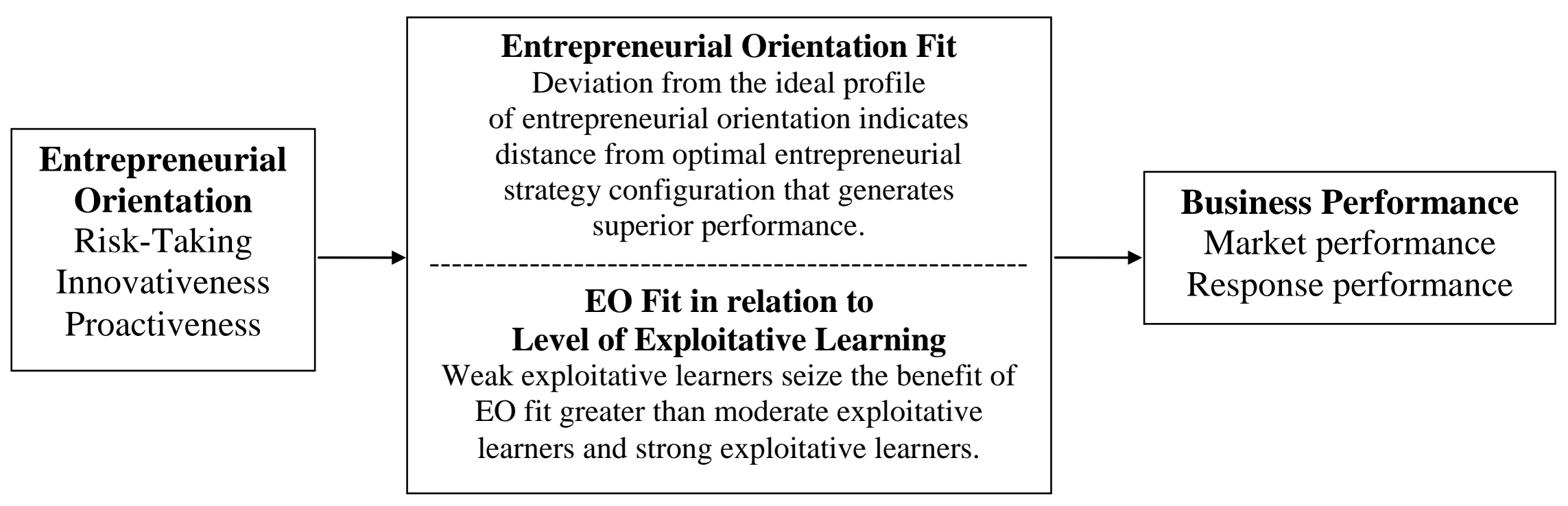

